\section{NCL DENTAL NURSING TEAM CUSTOM FITTED WITH SPECIALIST PPE}

Students and staff at New College

Lanarkshire (NCL) are being fitted with bespoke personal protective equipment (PPE) vital for undertaking work

placements in dental surgeries.

Scotland's Chief Dental Officer, Tom Ferris, and Paul Cushley, Dental Director for NHS National Services Scotland (NHS NSS), visited the College to see personalised fitting sessions of the specialist equipment required for performing aerosol-generating procedures (AGPs)

More than 200 students and 13 staff in NCL's dental nursing team are undergoing fitting sessions at the state-of-the-art dental suites in the Coatbridge Campus.

The FFP3 Mask is used to protect against respiratory borne pathogens. All dental nursing staff and students must be 'face fit tested' to ensure that they can achieve a suitable fit of the mask and that it operates at the required efficiency.

The cost is being covered by the Scottish Government and supplied by NHS Nationa Services Scotland to around 4,000 locations across Scotland. The dental team at NCL estimates the saving to the College instead of buying the PPE to be in the region of $£ 13,000$.

Leading safety supplier Arco has been commissioned by NHS NSS, with costs covered by the Scottish Government, to carry out the fittings lasting up to 30 minutes each.

The fitting involves a series of seven exercises, including breathing, head

Left to right: Paul Cushley, Dental Director for NHS NSS with Kate Wilson, Curriculum and I Quality Leader for Dental at New College Lanarkshire, and Tom Ferris, Scotland's Chief I Dental Officer

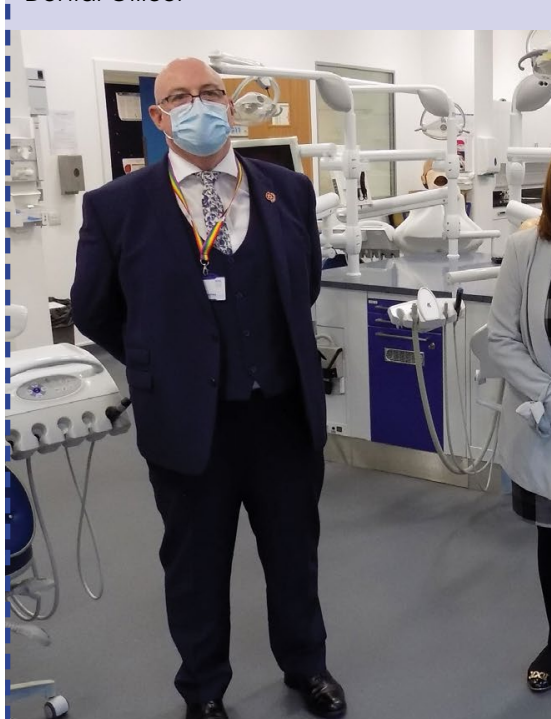

movements and bending. The monitor measures the quality of the air in the mask versus the environmental air quality to generate an overall 'fit factor.'

After fitting, participants receive a certificate detailing their specified mask type and brand, which will allow students to return to work placements, and lecturers and assessors to observe their progress in surgeries.

NHS NSS authorises the distribution of PPE from the Scottish Government to educational establishments and training providers.

Kate Wilson, Curriculum and Quality Leader for Dental at New College

Lanarkshire, said: 'The PPE is invaluable to us as a team. In the first instance, we are using it for demonstration purposes in our classrooms, and then it becomes mandatory for use by our students during the Dental Practice Placement element of their studies.

'The pandemic has greatly impacted on our profession given that it has required all dental staff to be retrained in the wearing of COVID PPE, which some have found difficult.

'Being custom-fitted with specialist face masks will ensure that our students and staff can be safe, comfortable and protected while carrying out their studies and their duties.

For more information on New College Lanarkshire's range of courses in dental nursing, visit https://www.nclanarkshire. ac.uk/courses/dental-nursing.

\section{SUBMISSIONS INVITED FOR OUTSTANDING INNOVATION AWARD}

The British Society of Paediatric Dentistry's (BSPD's) Outstanding Innovation Award (OIA), which celebrates inspiring and innovative schemes to improve the oral health of children, enters its sixth year in 2022. Entries are invited from people who have established a scheme with a demonstrable impact on children's oral health. By creating positive publicity around innovative schemes, BSPD's aim is to encourage, promote and disseminate good practice.

The prize for the winner is free attendance for a day of the BSPD conference and the opportunity to make a presentation. The winner of the Outstanding Innovation Award for 2021 was Simon Hearnshaw who entered on behalf of the North Yorkshire and Humber Local Dental Network for their 'In practice prevention scheme'. This innovative scheme which targeted families in deprived areas demonstrated that with the right approach, flexible commissioning works.

Other previous winners of OIA are: 2020 Linzi Maybin for her Happy Teeth Outreach project; 2019 Helen Rogers for establishing CONNECT Trainees; 2018 Ben Underwood for Brush DJ, the musicbased toothbrushing app; 2017 Ingrid Perry for Teeth Team.

The deadline for submission to be considered for OIA 2022 is 31 December 2021. For more information visit: https://www.bspd.co.uk/ Professionals/Awards-and-Prizes/ The-Outstanding-Innovation-Award.

\section{Reception and telephone skills}

The British Dental Association (BDA) is holding an online training event on reception and telephone skills for the whole dental team on 10 December. It will take place from 09:00 until 13:00 For more information and to book visit https://www.bda.org/events/Pages/ Reception-and-telephone-skills-Friday10-December-ONLINE.aspx. 